\title{
GÊNEROS DISCURSIVOS: UM OLHAR SOBRE A ENTREVISTA DE SELEÇÃO DE EMPREGO SOB A PERSPECTIVA DE BAKHTIN
}

\section{DISCOURSIVE GENRES: AN OVERVIEW ON JOB INTERVIEWS UNDER BAKHTIN'S PERSPECTIVES}

\section{Francisca Janete da Silva Adelino}

Doutor em Linguística pela Universidade Federal da Paraíba - UFPB, Paraíba (Brasil). E-mail: janeteadelino@ hotmail.com

\section{Erivaldo Pereira do Nascimento}

Doutor em Linguística pela Universidade Federal da Paraíba - UFPB, Paraíba (Brasil). E-mail: erypn@hotmail.com 


\title{
GÊNEROS DISCURSIVOS: UM OLHAR SOBRE A ENTREVISTA DE SELEÇÃO DE EMPREGO SOB A PERSPECTIVA DE BAKHTIN
}

\begin{abstract}
RESUMO
Este trabalho investiga o gênero entrevista de seleção de emprego, a partir das contribuições de Bakthin (2011). Metodologicamente, a pesquisa caracteriza-se como teórica e documental, de caráter descritivo e interpretativo. O corpus é composto por três entrevistas gravadas em uma instituição de ensino superior de Natal - RN durante o processo de recrutamento e seleção de professores para cursos técnicos profissionalizantes, vinculados ao Pronatec. A pesquisa objetiva analisar o conteúdo temático, a estrutura composicional e o estilo verbal do gênero em tela, e, além disso, especificamente, busca identificar alguns elementos linguístico-discursivos que são característicos do gênero. As análises revelam que o conteúdo temático é marcado por temas relativos à experiência profissional, disponibilidade de tempo, planejamento de aula, remuneração, horário, local das aulas e perfil dos alunos; além de uma introdução, cujo objetivo é abrir esse evento social com os cumprimentos e a contextualização do processo seletivo, e também de um encerramento, composto de agradecimentos e de informações relacionadas às próximas fases do processo seletivo. Quanto à construção composicional, esse gênero organiza um evento oficial dentro de uma esfera social, que é coordenado por um representante legal com poderes para conduzir o evento, por meio de questionamentos relativos ao propósito do cargo. Sobre o estilo, observou-se o uso de recursos tais como a da entonação de ênfase; da repetição; de marcadores conversacionais de concordância e de construções frasais na interrogativa.
\end{abstract}

Palavras-chave: Gêneros discursivos. Entrevistas de seleção de emprego. Elementos caracterizadores.

\section{DISCOURSIVE GENRES: AN OVERVIEW ON JOB INTERVIEWS UNDER BAKHTIN'S PERSPECTIVES}

\begin{abstract}
This paper investigates the discoursive genre called job interview, based on the theoretical contributions from Bakhtin (2011). Methodologically, the research is characterized as a theoretical and documentary, descriptive and interpretative investigation. The corpus consists of three interviews recorded at a higher education institution, from Natal - RN, during the process of recruitment and selection of teachers for vocational technical courses at Pronatec. The research aims to analyze the thematic content, the compositional structure and verbal style genre-screen, and also tries to identify some linguistic-discoursive elements that characterize the genre. The analysis reveals that the thematic content is characterized by issues related to professional experience, time availability, lesson planning, compensation, time, location of classes and students profile. There is also an introduction, which purpose is to open this social

Revista de Gestão e Secretariado-GeSec, São Paulo, v. 8, n. 2, p 107-227, Mai./Ago.
\end{abstract}


event with greetings and the contextualization of the selection process, and a closure, that consists of thanking, and also provides information related to the next steps of the selection process. As regards the compositional structure, this genre organizes an official event in a social sphere, which is coordinated by a legal representative empowered to conduct the event, through questions concerning the purpose of the office. Considering the style, we note the use of resources such as intonation emphasis; repetition; conversational markers of agreement and phrasal constructions in the interrogative form.

Keywords: Discoursive genres. Job interviews. Characteristic elements.

\section{INTRODUÇÃO}

A concepção de gênero adotada neste trabalho é a bakhtiniana segundo a qual os gêneros discursivos são tipos relativamente estáveis de enunciados, que são delimitados a partir de três elementos caracterizadores, a saber: o conteúdo temático, a construção composicional e o estilo linguístico, sendo este último entendido como a seleção operada nos recursos da língua: recursos lexicais, fraseológicos e gramaticais. Esses três elementos compõem, de maneira indissoluta, o enunciado.

Nessa perspectiva, o presente artigo tem por objetivo analisar o conteúdo temático, a construção composicional e o estilo linguístico do gênero discursivo entrevista de seleção de emprego, no intuito de identificar alguns elementos linguísticodiscursivos que são característicos do gênero. Trata-se de um recorte da nossa tese ${ }^{1}$ de doutorado intitulada $\mathrm{Na}$ trilha dos modalizadores: perscrutando os jogos argumentativos no gênero entrevista de seleção de emprego, defendida em junho de 2016 no Programa de Pós-Graduação em Linguística - Proling da Universidade Federal da Paraíba - UFPB. Este trabalho é filiado ao Laboratório Semântico-Pragmático de Texto - LASPRAT e ao projeto de Estudos Semânticos Argumentativos de Gêneros do Discurso - ESAGD, ambos da UFPB.

O delineamento metodológico desta investigação constitui-se de uma pesquisa teórica e documental de caráter descritivo e interpretativo, que intentará aplicar os critérios estabelecidos por Bakhtin (2011) - o conteúdo, a construção composicional e o estilo para a definição do gênero discursivo entrevista de seleção de emprego.

Quanto ao material examinado - as entrevistas de seleção de emprego coletadas -, ainda não recebeu um tratamento analítico, motivo pelo qual essa investigação se configura em uma pesquisa documental (Gil, 1999). Entende-se, por documentos, as entrevistas transcritas. Assim, são elas que constituem a fonte de dados deste trabalho.

O corpus é composto de três entrevistas de seleção de emprego gravadas em áudio, durante o processo de recrutamento e seleção de professores, que foi realizado em um centro universitário do estado do Rio Grande do Norte $^{2}$, na cidade de Natal RN. Assim, buscou-se, a partir do corpus, realizar uma análise interpretativa em

\footnotetext{
${ }^{1}$ A tese de doutorado objetivou investigar os modalizadores mais recorrentes na entrevista de seleção de emprego e, a partir da ocorrência e do funcionamento argumentativo desses modalizadores, identificar quais deles são característicos dos discursos dos locutores. A referida tese encontra-se disponível em http://tede.biblioteca.ufpb.br:8080/handle/tede/8559

${ }^{2} \mathrm{O}$ nome do centro universitário no qual realizamos a coleta do corpus não será revelado tendo em vista o compromisso que assumimos junto ao Conselho de Ética.

Revista de Gestão e Secretariado-GeSec, São Paulo, v. 8, n. 2, p 107-227, Mai./Ago.
}

2017. 
conformidade com os aspectos teóricos desenvolvidos neste estudo, por meio dos seguintes procedimentos: a) transcrição das entrevistas seguindo as normas adotadas pelo projeto NURC-Brasil; b) leitura e releitura de cada uma das entrevistas, no intuito de ser o mais fiel possível ao áudio; c) mapeamento do corpus como um todo e definição de códigos de identificação: L1 (entrevistador), L2 (entrevistado), EE01 (entrevista de seleção de emprego 1), EE02 (entrevista de seleção de emprego 2) e EE03 (entrevista de seleção de emprego 3).

Vale ressaltar que decidimos fazer a análise do corpus e a discussão dos resultados concomitantemente à resenha teórica. Dessa forma, o estilo linguístico, o conteúdo temático e a estrutura composicional das entrevistas de seleção de emprego, assim como os seus aspectos característicos são exemplificados, discutidos e interpretados ao longo da própria discussão e apresentação da base teórica.

Sendo assim, apresenta-se a noção de gênero discursivo postulada por Bakhtin (2011) porque este considera os gêneros em uma perspectiva sócio-interacionista. Nesse trajeto, as discussões sobre alguns elementos característicos do gênero entrevista, tais como: a assimetria, a organização tópica, a alternância dos locutores, o par perguntaresposta e a repetição, foram construídas com base, principalmente, nos estudos advindos de Marcuschi (1995), Fávero (2000), Espíndola (2004), Fávero, Andrade e Aquino (2005), Jubran (2006) e Koch (2010).

O presente trabalho está dividido em cinco partes. Nesta parte introdutória, situa-se o leitor sobre em que consiste o objeto de estudo sob o qual se encontra esta investigação. Foca-se no ponto de vista através do qual ele foi apreciado, apresenta-se o objetivo e as considerações metodológicas. Na segunda parte, faz-se uma reflexão a respeito dos estudos sobre os gêneros discursivos. Na terceira parte, aprofunda-se essa resenha e descrevem-se os aspectos característicos da entrevista de seleção de emprego enquanto gênero. $\mathrm{Na}$ quarta, discutem-se os elementos da oralidade e do estilo linguístico do gênero em estudo. Por fim, nas considerações finais, são relacionados alguns pontos dos achados da pesquisa.

\section{GÊNEROS DISCURSIVOS: UM OLHAR SOBRE A ENTREVISTA DE SELEÇÃO DE EMPREGO}

Na noção de gênero discursivo proposta por Bakhtin (2011), a linguagem é um fenômeno social, histórico e ideológico. Nesse sentido, o autor define os gêneros discursivos como formas relativamente estáveis de enunciados, elaborados de acordo com as condições específicas de cada campo da comunicação humana. Assim, o enunciado é o resultado da interação entre sujeitos sócio-históricos e compreende aspectos verbais e não verbais. De outro modo, o enunciado é sempre considerado em termos de resposta a outros enunciados, é um elo na corrente da comunicação e reflete e refrata as condições comunicativas.

Nos escritos de Bakhtin, de forma geral, encontra-se a tese de que a enunciação é de natureza social. O enunciado sempre é direcionado para um outro, para o interlocutor. Segundo Bakhtin e Volochinov (2009, p. 116), “[...] a enunciação é o produto da interação de dois indivíduos socialmente organizados e, mesmo que não haja um interlocutor real, este pode ser substituído pelo representante médio do grupo social ao qual pertence o locutor". O outro, o interlocutor, é fundamental para a noção de enunciação proposta pelo Círculo - grupo de intelectuais que se reunia regularmente, de 1919 a 1920 para debater ideias sobre a definição do objeto língua, sobretudo no sentido de lidar com os elementos que foram subtraídos do objeto da linguística no ato

Revista de Gestão e Secretariado-GeSec, São Paulo, v. 8, n. 2, p 107-227, Mai./Ago. 
de sua inscrição no campo da ciência (Faraco, 2003). Além disso, a noção de enunciado, em Bakhtin, não pode ser dissociada da noção de gêneros discursivos, já que, para o estudioso russo, os gêneros são conceituados como sendo tipos relativamente estáveis de enunciados. Convém destacar que, embora alguns autores marquem distinções da terminologia gêneros discursivos em relação aos gêneros textuais, não é nosso objetivo entrar nessa discussão. Portanto, esses termos são usados aqui como equivalentes, dando preferência ao primeiro.

Bakhtin (2011) considera os aspectos individuais e sociais, sempre vinculados a uma situação concreta de uso, na qual os enunciados devem ser vistos na sua função no processo de interação. Portanto, a verdadeira natureza da linguagem encontra-se na interação socioverbal, em que o homem é essencialmente social e a linguagem é ideológica. Desse modo, cada esfera do uso da língua potencializa seus próprios gêneros, determinando as formas genéricas e relativamente estáveis de manifestação dos discursos.

Os gêneros compreendem uma variedade inesgotável. São diversos porque diversas são as esferas de atividade humana, que produzem uma infinidade de gêneros. Diante da diversidade de gêneros discursivos, esse autor, de uma forma geral, não se preocupa em classificá-los tipologicamente, talvez justamente pela infinidade, riqueza e variedade de enunciados/textos. Entretanto, ele propõe uma classificação ou divisão entre gêneros discursivos primários (simples) e secundários (complexos).

Os gêneros primários são enunciados nascidos em circunstâncias de comunicação verbal espontânea, tais como os gêneros da vida cotidiana, como a réplica do diálogo, o bate-papo e a piada. Esses gêneros enquadram-se numa esfera discursiva imediata e nas relações sociais mais diretas. Entretanto, deve-se tomar o devido cuidado de não associar, ingenuamente, os gêneros primários à oralidade e nem os secundários à escrita, porque existe uma interdependência entre essa classificação, ou seja, há gêneros primários escritos, como o diário, e gêneros secundários orais, como a palestra, a conferência, a aula etc.

Os gêneros discursivos secundários, por sua vez, surgem nas condições de um convívio cultural mais complexo e relativamente muito desenvolvido e organizado (predominantemente o escrito). Bakhtin (2011, p. 263) enfatiza que "no processo de sua formação eles incorporam e reelaboram diversos gêneros primários (simples), que se formaram nas condições da comunicação discursiva imediata".

Os gêneros secundários, apesar de a modalidade escrita ser predominante, não é a única, haja vista a existência de textos do tipo conferências acadêmicas, religiosas, sermões, reportagens, memórias, dentre outros, que se configuram como gêneros secundários.

A entrevista de seleção de emprego, mais particularmente, pode ser considerada como pertencente ao grupo dos gêneros secundários, considerando que tal gênero organiza uma situação complexa e mais institucionalizada. Além disso, o gênero entrevista de seleção de emprego pode incorporar e reelaborar gêneros primários como, por exemplo, o diálogo informal.

Esse aspecto será exemplificado no recorte inicial da EE03 em que o entrevistador, doravante (L1), faz algumas perguntas ao entrevistado, doravante (L2):

\section{Entrevista de seleção de emprego 03 (EE03)}

1. L1 boa tarde... sou a professora Maria... coordenadora do curso técnico em

Revista de Gestão e Secretariado-GeSec, São Paulo, v. 8, n. 2, p 107-227, Mai./Ago.

2017. 


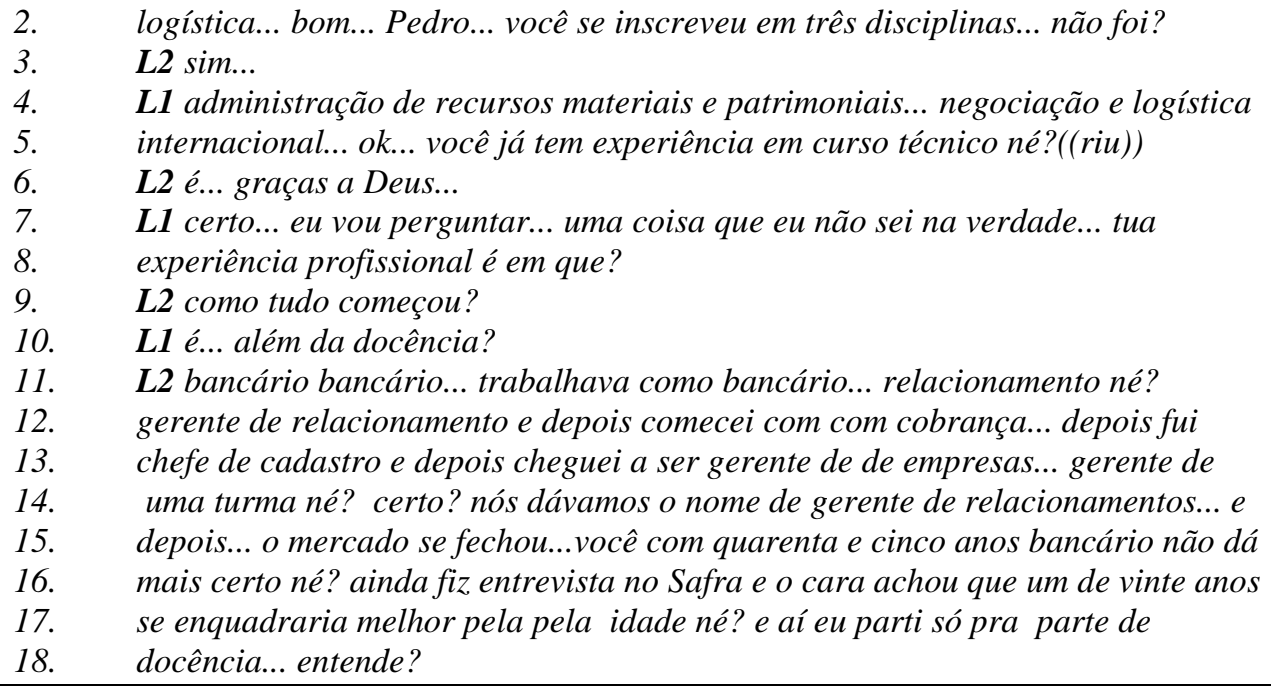

Para efeito de exemplo, foquemos exclusivamente na fala do entrevistado. São perceptíveis os traços dos enunciados nascidos em circunstâncias de comunicação verbal espontânea. Embora esteja em uma situação marcada pelo formalismo e pelas regras que regem a esfera acadêmica, L2 se apropria dos traços que marcam os gêneros da vida cotidiana como a réplica do diálogo. Observa-se o uso do marcador conversacional de final de segmentos tópicos "né", a repetição do marcador de narrativa "depois", a presença de gírias "o cara achou", forte apelo ao acordo do interlocutor (L1) por meio de marcadores conversacionais de concordância "certo?" e "entende?".

Percebe-se que a entrevista de seleção de emprego, por ser oral, é atravessada pelos traços da fala cotidiana, daqueles gêneros que se enquadram numa esfera discursiva imediata e nas relações sociais mais diretas. Outro aspecto importante é que há uma interdependência dos gêneros e o que os distingue é a ligação com as esferas de uso da linguagem e a forma de elaboração. Desse modo, para cada esfera de produção, de circulação e de recepção de discursos, existem gêneros apropriados.

Ainda, sobre a natureza múltipla dos gêneros discursivos, Bakhtin (2011) afirma que os gêneros possuem três elementos básicos, quais sejam: o estilo, o conteúdo temático e a construção composicional. Esses elementos formam uma unidade orgânica e constituem a unidade de sentido: o enunciado concreto.

$O$ estilo é considerado pelo autor supracitado, como o elemento na unidade de gênero de um enunciado. Nas colocações desse estudioso, todo enunciado, seja ele oral ou escrito, primário ou secundário, ligado a qualquer campo da comunicação discursiva, apresenta traços da individualidade do falante (ou de quem escreve). Em outros termos, todo texto passa a ter um estilo individual. É importante observar que, além do estilo individual, que se manifesta em cada texto (enunciado, em termos bakhtinianos), Bakhtin (2011, p. 266) postula a existência de um estilo linguístico particular para cada gênero discursivo. Conforme o autor, em "[...] cada campo existem e são empregados gêneros que correspondem às condições específicas de dado campo; é a esses gêneros que correspondem determinados estilos".

Desse modo, cada gênero discursivo, por ser produzido e circular em determinada esfera de atividade humana, possui um estilo linguístico peculiar (recursos fraseológicos, gramaticais e lexicais) que são próprios dessa esfera. No entanto, é importante considerar que, mesmo dentro da mesma esfera de atividade humana, ocorrerão variações do estilo linguístico de um gênero para outro. 
A esse respeito, Nascimento e Silva (2012) contribuem dizendo que o estilo verbal de uma ata, por exemplo, não é necessariamente o mesmo de um memorando, justamente por servirem a propósitos comunicativos distintos. Assim, as expressões linguísticas, o nível de formalidade, a coordenação das frases e sentenças vão ser diferentes em um gênero e outro. Isso implica que o estilo linguístico de um determinado gênero discursivo está intrinsecamente relacionado não só com a esfera de atividade humana em que esse gênero é produzido, mas também com o propósito comunicativo desse gênero, ou seja, com o seu funcionamento linguístico-discursivo e sua utilização na esfera em que é produzido e/ou circula.

O estilo linguístico individual de cada gênero revela algumas peculiaridades do enunciado concreto. São eles: alternância dos sujeitos do discurso, autor e conclusibilidade. Quanto ao primeiro aspecto, é dito que "os limites de cada enunciado concreto como unidade da comunicação discursiva são definidos pela alternância dos sujeitos do discurso, ou seja, pela alternância dos falantes" (Bakhtin, 2011, p. 275). É a alternância entre sujeitos que cria os limites precisos do enunciado nos diversos campos da atividade humana e da vida.

Ao tratar da segunda peculiaridade, denominada de autor, Bakhtin (2011, p. 279) explica que, ao estabelecer fronteiras com outros enunciados, o enunciado concreto adquire uma individualidade, um caráter interno, ou seja, "[...] o sujeito do discurso neste caso o autor de uma obra - aí revela a sua individualidade no estilo, na visão de mundo, em todos os elementos da ideia de sua obra", explica o estudioso. Essas marcas da individualidade criam justamente os princípios interiores específicos que a separam de outras obras a ela vinculadas no processo comunicativo discursivo de um dado campo cultural.

O terceiro aspecto, a conclusibilidade, está intimamente vinculado à primeira, ou seja, a alternância dos sujeitos do discurso. No tocante a essa questão, Bakhtin (2011, p. 280) afirma que "a conclusibilidade do enunciado é uma espécie de aspecto interno da alternância dos sujeitos do discurso [...]".

Dessas considerações, ressaltamos, portanto, que a conclusibilidade à qual Bakhtin se refere implica algumas coisas, como: instaurar um efeito de fim do enunciado, possibilidade de resposta e possibilidade de ocupar uma posição em relação ao enunciado. Ao analisarmos o gênero entrevista de seleção de emprego, é possível flagrarmos esses aspectos configuradores do estilo. Todas as entrevistas apresentam uma estrutura comum como, por exemplo, a alternância entre perguntas e respostas. Ao mesmo tempo, as marcas linguísticas e a mobilização de estruturas frasais variam de acordo com os participantes (entrevistador e entrevistado). O fragmento da EE03 mencionado anteriormente, por exemplo, mostra que é predominante o uso de construções frasais na interrogativa. E isso ocorre porque o entrevistado lança mão desse recurso para estabelecer e manter o contado com o entrevistador.

Assim, ao ser perguntado, por L1, sobre a experiência profissional, L2 responde, fornecendo a informação pedida, mas sempre procurando o acordo de L1 através do uso de marcadores conversacionais "né" e "certo", com o intuito de solicitar a confirmação da sua fala, conforme podemos observar no exemplo que se segue:

\section{Entrevista de seleção de emprego 03 (EE03)}

Revista de Gestão e Secretariado-GeSec, São Paulo, v. 8, n. 2, p 107-227, Mai./Ago.

2017. 
11. L2 bancário bancário... trabalhava como bancário... relacionamento né?

12. gerente de relacionamento e depois comecei com com cobrança... depois fui

13. chefe de cadastro e depois cheguei a ser gerente de de empresas... gerente de

14. uma turma né? certo?

O uso dos marcadores conversacionais "né" e "certo" é bastante recorrente na entrevista em questão. Logo, os participantes envolvidos, ao mesmo tempo em que seguem um estilo linguístico estabelecido pelo próprio gênero entrevista de seleção de emprego, imprimem também um estilo individual que difere cada entrevista em particular das outras entrevistas realizadas no mesmo local, para o mesmo cargo.

Quanto à conclusibilidade, a entrevista de seleção de emprego apresenta características que marcam seu início e seu término (conclusão). Nesse gênero, encontramos enunciados que são típicos de seu início e outros que sinalizam sua finalização. Em ambos os casos, é sempre o entrevistador (L1) quem possui as prerrogativas para estabelecer limites, ou seja, nesse gênero não é esperado que o entrevistado conduza a entrevista e muito menos que conclua esse evento social.

Exemplificamos a seguir a introdução e a conclusão da entrevista de seleção de emprego 01:

\section{Entrevista de seleção de emprego 01 (EE01)}

Introdução

1. L1 prof. Pedro...

2. L2 isso...

3. $\mathbf{L} 1$ prof. Pedro... muito bem vindo...

4. L2 obrigado...

5. L1 seja bem vindo... obrigado por dispor seu tempo tamBÉM... nós como

6. instituição... assim... é:: estamos estamos é:: mais mais uma vez... abrindo esse...

7. processo seletivo... e a intenção nossa... é:: quer dizer... é:: o objetivo na

8. verdade... é ampliarmos o nosso quadro... as demandas vão surgindo... e.: com

9. essas demandas vão surgindo é:: é:: tem-se crescido a a necessidade de termos

10. mais professores... e:: no momento abrimos uma seleção nesse edital que foi

11. lançado agora... em outubro... pra:: seleção de professores... e :: um deles... e

12. uma e uma área... a área de radiologia veterinária... sou coordenador do curso

13. de radiologia e:: eu fiz questão de colocar inclusive na grade não tinha... não é

14. toda escola que tem a disciplina de radiologia veterinária... você sabe muito bem

15. disso...

16. L2 ahn ahn...

17. L1 mas... eu já vejo por outro lado... acho que tem que ter sim... tem a

18. necessidade... é um mundo que tá crescendo muito... uma área que está

19. crescendo muito...

20. L2 com certeza...

21. L2 com certeza...

Conclusão

262. L1 professor... MUIto obrigado... o senhor tem alguma observação... alguma

263. coisa?

264. L2 não... па̃o...

265. L1 MUIto obrigado... espero... obrigado pela nossa conversa e.: entrarei em

266. contato com o senhor AINda hoje (...)

267. L2 tá bom...

268. L1 para já dá um posicionamento e desejo sucesso para o senhor...

Revista de Gestão e Secretariado-GeSec, São Paulo, v. 8, n. 2, p 107-227, Mai./Ago. 
269. L2 obrigado pela oportunidade...

Por ser um gênero que organiza um acontecimento oficial dentro de uma esfera social, a entrevista de seleção de emprego apresenta uma introdução em que o entrevistador oficializa o início do evento, dando boas vindas ao entrevistado e apresentando a instituição da qual ele faz parte e é representante. Com isso, os papéis de cada participante são estabelecidos e um acordo é firmado. Nesse primeiro momento, é fundamental que o entrevistado entre em acordo com o entrevistador. E aquele marca seu acordo com este por meio da expressão "com certeza", possibilitando o desenvolvimento da entrevista. É importante observar que o marcador "com certeza" usado por L2 traz também uma noção de comprometimento.

Do mesmo modo como conduziu a introdução da entrevista de seleção de emprego, o entrevistador sente-se investido de poderes, a ele conferidos pela instituição que representa, para estabelecer uma conclusão para a referida entrevista. Os agradecimentos sinalizam para o entrevistado que a entrevista caminha para o fim. Ao mesmo tempo, ao perguntar se o entrevistado tem "alguma observação", "alguma coisa?", o entrevistador procura concluir na certeza de que tudo aquilo que poderia ser dito, por parte do entrevistado, realmente foi dito. Ao confirmar com um "não", o entrevistado assinala o acordo de pôr fim ao enunciado concreto - ao gênero entrevista de seleção de emprego.

Cada enunciado, ou cada réplica, nos dizeres de Bakhtin (2011, p. 275), “por mais breve e fragmentária que seja, possui uma conclusibilidade específica ao exprimir certa posição do falante que suscita resposta, em relação à qual se pode assumir uma posição responsiva". Esses movimentos configuradores do gênero entrevista de seleção de emprego levam-nos a perceber que cada ato de linguagem é produzido tendo em vista um auditório social e o enunciado reflete tais condições. A dupla face é marca da enunciação, pois, de um lado, o enunciado procede de alguém e, de outro lado, ele se dirige para alguém. Cada palavra que constitui a entrevista em questão constitui justamente o produto da interação do locutor e do ouvinte. Toda palavra serve de expressão de um em relação ao outro (Bakhtin \& Volochinov, 2009).

Estando ambos acordados sobre o término da entrevista de seleção de emprego, resta ao entrevistador anunciar o fim. Isso é feito por meio de agradecimentos e felicitações, marcando a cordialidade do ato interativo. Os recursos linguísticos destacados e que marcam a introdução e a conclusão da entrevista, evidentemente, constituem o estilo, ou melhor, referem-se a um modo de apresentação do conteúdo traduzido no plano composicional do gênero por meio da seleção de recursos lexicais, fraseológicos e gramaticais da língua.

Para Bakhtin (2011, p. 291), “[...] quando escolhemos as palavras para o enunciado é como se nos guiássemos pelo tom emocional próprio de uma palavra isolada: selecionamos aquelas que pelo tom, correspondem à expressão do nosso enunciado e rejeitamos as outras". O estilo é, pois, uma seleção de certos meios lexicais em função da imagem do interlocutor e de como se presume sua compreensão responsiva ativa do enunciado.

O conteúdo temático está no domínio do sentido que envolve um determinado gênero, pois a diversidade dos gêneros do discurso é infinita, heterogênea. Sendo assim, esse elemento diz respeito às escolhas e propósitos comunicativos do locutor em relação ao assunto abordado, ou seja, a um domínio do objeto e do sentido.

$\mathrm{Na}$ compreensão de Bakhtin, o conteúdo temático tem a ver com a exauribilidade do objeto e do sentido. Para este estudioso, "o objeto é objetivamente

Revista de Gestão e Secretariado-GeSec, São Paulo, v. 8, n. 2, p 107-227, Mai./Ago. 
inexaurível, mas ao se tornar tema do enunciado". Assim, o objeto ganha uma relativa conclusibilidade em determinadas condições, em certa situação do problema, conforme assevera (Bakhtin, 2011, p. 281, grifo do autor). Dessa forma, o conteúdo temático de um enunciado concreto representa sempre um recorte, um ponto de vista do locutor diante de um objeto do discurso, ou seja, diante daquilo de que se fala ou escreve.

Esse aspecto do conteúdo temático nos leva a concluir que os enunciados concretos que circulam socialmente apresentam pontos de vista e avaliações sobre determinado tema. Tomemos, por exemplo, a mesma entrevista de seleção de emprego da qual já mostramos a introdução e a conclusão. Diante de tal gênero, a questão é: essa entrevista é sobre o quê? Qual o seu tema? É perceptível que a entrevista de seleção de emprego versa, principalmente, sobre a vida profissional do entrevistado. As perguntas elaboradas pelo entrevistador visam extrair informações sobre a experiência profissional do sujeito entrevistado e, consequentemente, o conteúdo de tal entrevista gira em torno do relato dessas experiências. $O$ fragmento que se segue exemplifica o conteúdo temático:

\section{Entrevista de seleção de emprego 01 (EE01)}

34. L1[ ] é formado em medicina veterinária...

35. L2 sou formado em medicina veterinária...

36. $\quad \mathbf{L}$ me conte um pouco do senhor... por favor...

37. L2 eu sou formado em medicina veterinária... me formei pela Ufesa em 2011

38. e:: sempre durante a minha vida acadêmica fiz estágio na área de pequenos

39. animais... fiz alguns poucos estágios também com grandes animais mas sempre

40. gostei mais da área de pequenos... então... já passei... a gente tinha nos nos

41. nossos estágios... que a gente chama de internato né... a gente passa por todos

42. os setores de um hospital... então passei pela área de cirurgia... pela área

43. clínica... pela área de anestesia... (...)

44. L1 pela área de... radiologia?

45. L2 pela área de radiologia TAMbém.. e... fui fazer o meu mestrado assim que

46. acabei a faculdade na farmacologia né... fui pra São Paulo fazer na USP fizo

47. mestrado em farmacologia lá... porque sempre acho importante... a

48. farmacologia é uma ferramenta dinâmica pra você usar na clínica... na

49. cirurgia... pra você usar na inspeção dos produtos de origem animal... enfim...

50. tá atrelado a tudo... é uma área que sempre gostei... também fui prá lá... quando

51. cheguei em São Paulo fiquei trabalhando numa clínica durante pouco tempo

52. MESmo... porque... como eu fui bolsista Fapec eles pediam exclusividade e aí

53. sempre rolava aquele medo né... de alguém denunciar... aquela coisa... então...

54. eu saí da clínica que eu trabalhava em São Paulo... e aí eu me dediquei só ao

55. mestrado... e aí terminei o meu mestrado e... é... abriu seleção para o curso de

56. veterinária da Unp... fiz a seleção... passei e tô lá também...

57. L1 o senhor é professor do curso de graduação de veterinária da Unp?

58. L2 de graduação... não só de veterinária... mas como o meu mestrado

59. em farmacologia foi na área básica... então... eu ensino disciplinas é::

60. relacionadas a farmacologia e farmacologia pra enfermagem... pra

61. $\quad$ nutrição... pra outros cursos (...)

Conforme é possível perceber nas linhas 33, 35, 43 e 56 da EE01, o objetivo de L1 é extrair informações sobre a formação e experiência profissional de L2. A partir daí, L2 passa a fazer um relato de sua vida profissional, começando pela área de formação, estágios, mestrado, professor do curso de graduação de veterinária. Ao relacionar esse trecho à luz do que diz Bakhtin (2011), a temática é construída em torno da vida profissional de L2. Assim, um outro sujeito que assumisse a posição de L1(entrevistador) apresentaria a vida profissional de L2 (entrevistado) de um ponto de

Revista de Gestão e Secretariado-GeSec, São Paulo, v. 8, n. 2, p 107-227, Mai./Ago. 
vista diferente. Desse modo, na entrevista de seleção de emprego, a própria vida profissional dos entrevistados se constitui o objeto principal, tema do enunciado concreto - do gênero entrevista de seleção de emprego - e esse tema é construído a partir da interação, do diálogo entre os participantes da entrevista.

Segundo Bakhtin e Volochinov (2009, p. 133), “o tema deve ser único. Caso contrário, não teríamos nenhuma base para definir a enunciação. $\mathrm{O}$ tema da enunciação é na verdade, assim como a própria enunciação, individual e não reiterável." Assim, compreende-se que, em cada enunciado, existe um tema que é único, individual, diferente do assunto, por exemplo, que pode ser repetido em enunciados distintos.

O tema de um enunciado, cabe dizer, é formado por dois elementos: 1) elementos verbais (as palavras, as formas morfológicas ou sintáticas, os sons, as entonações) e 2) elementos não verbais, ou seja, pelos elementos da situação contextual. Assim, os próprios elementos linguísticos juntamente com a situação contextual que envolve a realização da entrevista constroem o tema de cada entrevista de seleção de emprego. Cada entrevista, portanto, tem um tema individual e não reiterável e isso porque os sujeitos que são entrevistados são diferentes, mudando, também, a situação contextual.

Quanto à construção composicional, esta concerne a um tipo de estruturação e de conclusão de um todo do gênero. Bakhtin (2011, p. 282, grifo do autor) assevera que "falamos apenas através de determinados gêneros do discurso, isto é, todos os nossos enunciados possuem formas relativamente estáveis e típicas de construção do todo". Trata-se, portanto, de aspectos responsáveis pelas semelhanças existentes nos textos de um mesmo gênero. Em outras palavras, é o modo de organizar um determinado texto que caracteriza a sua estrutura composicional.

Conforme se observa nos exemplos apresentados anteriormente, o gênero entrevista de seleção de emprego apresenta estrutura composicional relativamente estável. É construído a partir de uma troca entre perguntas e respostas; apresenta uma introdução com boas-vindas aos entrevistados e uma breve apresentação dos objetivos pelos quais a instituição realiza a seleção; traz na conclusão felicitações e agradecimentos por parte do entrevistador. Além disso, conforme já comentado, o estilo de linguagem acopla variantes do cotidiano (dos gêneros primários) até aspectos mais formais - como o uso da linguagem acadêmica e empresarial, por exemplo (dos gêneros secundários).

Um aspecto importante, ainda, acerca dos três elementos estudados (estilo, conteúdo temático e estrutura composicional) é que eles "[...] estão indissoluvelmente ligados no todo do enunciado e são igualmente determinados pela especificidade de um determinado campo da comunicação" (Bakhtin, 2011, p. 262). Por estarem estritamente ligados aos campos da comunicação, uma vez que a linguagem organiza as atividades humanas, os gêneros discursivos apresentam grande diversidade, já que também diversos são os campos da atividade humana. Nesse sentido, os gêneros discursivos são formas de organização e de ação humana.

O próprio gênero discursivo não pode, contudo, ser entendido separadamente dos participantes da situação comunicativa em que esse gênero é produzido. Na perspectiva bakhtiniana, uma característica do enunciado concreto é que ele sempre une os participantes da situação comum como coparticipantes que conhecem, entendem e avaliam a situação de maneira igual. Vale salientar que a noção de ouvinte não é a mesma da perspectiva estruturalista. $\mathrm{O}$ ouvinte é entendido aqui como aquele que o próprio locutor leva em conta, a quem um enunciado é orientado e que, por consequência, intrinsecamente determina a estrutura do enunciado. As perguntas que L1

Revista de Gestão e Secretariado-GeSec, São Paulo, v. 8, n. 2, p 107-227, Mai./Ago. 
faz durante a entrevista, por exemplo, são elaboradas tendo em vista L2. Mesmo que tenham sido preparadas previamente, como é comum ocorrer nessa situação de interação verbal, tais perguntas são construídas porque L1 leva em conta o outro, L2. É importante destacar que, mesmo durante o processo de troca, as perguntas podem ser reformuladas, dependendo da participação de L2 no próprio processo de interação, em função da atitude responsiva do outro.

Após essa revisão da noção de gêneros discursivos em Bakhtin, discorre-se, no próximo tópico, sobre o gênero entrevista de seleção de emprego, aprofundando alguns aspectos característicos desse gênero discursivo.

\section{ASPECTOS CARACTERÍSTICOS DA ENTREVISTA DE SELEÇÃo DE EMPREGO}

Convém assinalar que a entrevista de seleção de emprego pode ser concebida, ainda, como sendo de natureza interacional, e sua organização marca a relação entre os participantes envolvidos no ato comunicativo.

Para ocorrer uma troca comunicativa, é satisfatório que dois ou mais falantes falem alternadamente. Além disso, é ainda necessário que esses falantes estejam engajados na troca e que deem sinais desse engajamento mútuo, recorrendo a diversos procedimentos de validação interlocutória. Assim, na interação face a face, o discurso é construído conjuntamente, o locutor e o interlocutor desenvolvem um trabalho colaborativo. No processo de construção desse gênero, essa interação é evidente. Inicialmente, é fundamental que ocorra um acordo entre entrevistador e entrevistado para que a interação possa fluir. Com o acordo estabelecido, percebe-se uma sequência alternada, uma troca comunicativa em que os turnos de fala se estabelecem. É importante destacar que os turnos de fala consistem, segundo Fávero, Andrade e Aquino (2005), na produção de um falante enquanto ele está com a palavra, incluindo sua possibilidade de silêncio. $O$ trecho que segue revela o fenômeno interativo do gênero aqui estudado.

\section{Entrevista de seleção de emprego 01 (EE01)}

56. L1 o senhor é professor do curso de graduação de veterinária da Unp?

57. L2 de graduação... não só de veterinária... mas como o meu mestrado

58. em farmacologia foi na área básica... então... eu ensino disciplinas é::

59. relacionadas a farmacologia e farmacologia pra enfermagem... pra

60. nutrição... pra outros cursos (...)

61. L1 pra outros cursos... quais os dias que o senhor o senhor leciona lá? perdão...

62. L2 eu leciono lá todos os dias...

63. L1 todos os dias? qual o horário?

64. L2 de manhã e... à tarde ou à noite... de manhã SEMpre... à tarde e à noite é

65. flexível esse horário...

66. L1 é flexível... teria algum problema do senhor assumir alguma coisa aqui?

67. L2 não... desde que eu seja informado com uma certa antecedência... pra

68. conseguir organizar esses horários... mas em relação à tarde e à noite num... de

69. $\operatorname{manh} \tilde{a}()(\ldots)$

70. L1 se houvesse a necessidade de já iniciarmos com o senhor em... já em

71. dezembro... teria algum problema?

72. $\mathbf{L} 2 N \tilde{O} O \ldots$ 
O par "pergunta x resposta" marca o trecho ora apresentado. Todas as falas de L1 são marcadas por ponto de interrogação. Assim, L1 exerce, no jogo interativo, a função que lhe é facultada pelo lugar social que ocupa, ou seja, ele age interativamente como representante da instituição e, por isso, visa extrair de L2 informações que possam interessar, ou não, à instituição oferecedora da vaga de emprego.

É possível observar que L2, ao colaborar interativamente com L1, fornece as informações solicitadas. No diálogo em análise, ainda, percebe-se que L2 interage com L1 de forma colaborativa - no sentido de que procura responder diretamente ao que se pede na pergunta - perguntas essas elencadas por L1. Dessa forma, L2 busca satisfazer ao conteúdo de cada pergunta sem se alongar em explicações secundárias. Isso permite aos falantes avançarem sobre diversos assuntos.

Nesse sentido, no gênero discursivo entrevista de seleção de emprego ocorre aquilo que Bakhtin (2011) denomina de a compreensão de uma fala viva, ou seja, na interação viva um enunciado é sempre acompanhado de uma atitude responsiva ativa. $\mathrm{Na}$ linha de pensamento desse estudioso, compreende-se que, na troca dialógica, todos os enunciados nascem como respostas e, consequentemente, aquele que era ouvinte torna-se locutor. Assim, na interação viva, o par locutor x ouvinte não é estanque, pois tais posições mudam constantemente.

Na perspectiva bakhtiniana, uma propriedade significativa da palavra é que ela resulta do "consenso entre indivíduos" e é, ao mesmo tempo, produzida por indivíduos. O gênero discursivo, desse modo, tem uma natureza dialógica no sentido de ser resultado do consenso entre sujeitos socialmente situados. Todo discurso, portanto, é marcado por essa relação de "consenso entre indivíduos".

Além disso, Koch (2010) também fornece elementos importantes sobre a organização geral da conversação. Segundo a autora, a conversação organiza-se em turnos, que consistem em cada intervenção de um dos participantes no decorrer da interação. Ela ainda explica que

[...] há as interações simétricas, como as conversas do dia-a-dia, em que todos os participantes têm igual direito ao uso da palavra; e as assimétricas, como entrevistas [...] em que um dos parceiros detém o poder da palavra e a distribui de acordo com a sua vontade (Koch, 2010, p. 80).

Destaca-se o fato de a autora citar a entrevista como exemplo de interações assimétricas. A entrevista é assim entendida porque é o entrevistador que, comumente, direciona o desenvolvimento de tal interação ao fazer questionamentos ao entrevistado. Logo, é a partir da ação daquele que busca informações (o entrevistador) que a entrevista é conduzida.

O diálogo assimétrico, portanto, ocorre justamente pela relação de desigualdade existente entre os membros participantes de um evento de fala. Essa desigualdade diz respeito aos papéis, às funções, aos lugares ocupados por cada interlocutor envolvido na construção da entrevista. Um é o lugar do entrevistador; outro é o lugar do entrevistado.

Marcuschi (1995, p. 82, grifo do autor) afirma que "[...] no discurso, poder relaciona-se às escolhas feitas em relação a, por exemplo, tópicos, estilos, estratégias etc., que se manifestam na própria interação verbal". Dessa forma, as relações de poder surgem no contexto da vida social em que o uso da língua tem um papel relevante.

Ao aprofundar os estudos sobre as noções de assimetria, de poder e de adequação na interação verbal, Marcuschi (1995) explica que as noções de igualdade e desigualdade de condições (de conhecimento e posição social) são traços constitutivos das relações interpessoais na interação verbal. As interações institucionais apresentam diferenças de status, competência e responsabilidade. Os papéis, no entanto, são 
complementares e as responsabilidades também. É o caso, por exemplo, da conversação em que um pergunta e o outro responde.

Nessa mesma perspectiva, Espíndola (2004, p. 83) postula que "[...] nas interações assimétricas, um dos participantes tem o direito de conduzir a interação". No caso da entrevista de seleção de emprego, conforme consta no trecho da EE01 apresentado anteriormente, é o entrevistador que escolhe sobre o que vai falar e a direção da conversação. A autora ainda acrescenta que nessa modalidade de interação, incluem-se as entrevistas de modo geral. Para essa estudiosa, a entrevista pertence à classe dos discursos institucionalizados assimétricos porque a maioria dos parâmetros reguladores do discurso institucionalizado assinala para esse resultado.

Fávero (2000) comenta que o caráter assimétrico da entrevista ocorre em função das relações de poder que marcam a interação entre entrevistador e entrevistado. Para a autora, os sujeitos envolvidos nesse evento desempenham papéis e condições distintos de participação no diálogo, exercendo um direcionamento maior ou menor na interação, de modo que o entrevistador pode meramente cumprir o papel de obter respostas ou dirigir de tal maneira que o entrevistado é conduzido às respostas préestabelecidas pelo entrevistador.

Assim, a assimetria é um aspecto que aponta para aquilo que abrange as relações sociais, mas que se materializa no texto. Em certo sentido, poderíamos dizer que o planejamento prévio e o par "pergunta-resposta" são marcas da assimetria, já que cabe ao entrevistador - e somente a ele - elaborar previamente as perguntas e direcionálas ao entrevistado. O inverso não costuma ocorrer, ou não é esperado, logo não é algo pertencente ao estilo do gênero entrevista.

Ao discorrer sobre o gênero em questão, Fávero (2000, p. 79) argumenta que a entrevista é um tipo especial de texto falado porque há normalmente um planejamento prévio por parte do entrevistador. Para a autora, o objetivo da entrevista "[...] é sempre o interrelacionamento humano, mas os direitos dos participantes não são os mesmos, pois o entrevistador faz as perguntas e oferece, em seguida, o turno ao entrevistado".

Segundo a visão dessa mesma pesquisadora, é possível dizer que esse gênero possui características comuns às da atividade conversacional espontânea, ou seja, das interações casuais; no entanto, difere em vários aspectos desse tipo de texto exatamente por apresentar características próprias, tais como o planejamento prévio dos tópicos a serem desenvolvidos durante o evento, o par "pergunta-resposta" e a assimetria, em que um dos participantes exerce o direito de iniciar, orientar, dirigir e concluir o tópico.

Sobre o planejamento, é dito que a entrevista tem diferentes graus de planejamento. Inicia com a preparação da pauta, seguido da entrevista propriamente dita e termina na edição. Há vários tipos de entrevista, tais como: a entrevista falada ao vivo, a entrevista falada, mas não ao vivo, a entrevista escrita, a entrevista por telefone etc. Para Fávero (2000), toda entrevista requer um planejamento, geralmente maior por parte do entrevistador do que do entrevistado.

Quanto ao par dialógico "pergunta-resposta”, Fávero (2000, p. 96) afirma que esse "[...] se configura como elemento imprescindível na organização do texto da entrevista, prestando-se a consolidar ou a modificar as relações entre os interlocutores [...] imprimindo um caráter vivo ao evento discursivo". As perguntas e respostas constituem estratégias utilizadas pelos interlocutores durante uma interação verbal, e podem ser utilizadas para introduzir, continuar, redirecionar ou mudar um tópico. Quanto à natureza das perguntas, estas podem oferecer pistas a respeito dos prováveis tipos de perguntas, tais como: pedido de informação; pedido de confirmação; pedido de esclarecimento etc. 
Para exemplificar as características do gênero entrevista de seleção de emprego, com base nas noções apresentadas sobre a assimetria, o planejamento prévio dos tópicos e o par "pergunta-resposta", apresentamos um trecho da EE02.

\title{
Entrevista de seleção de emprego 02 (EE02)
}

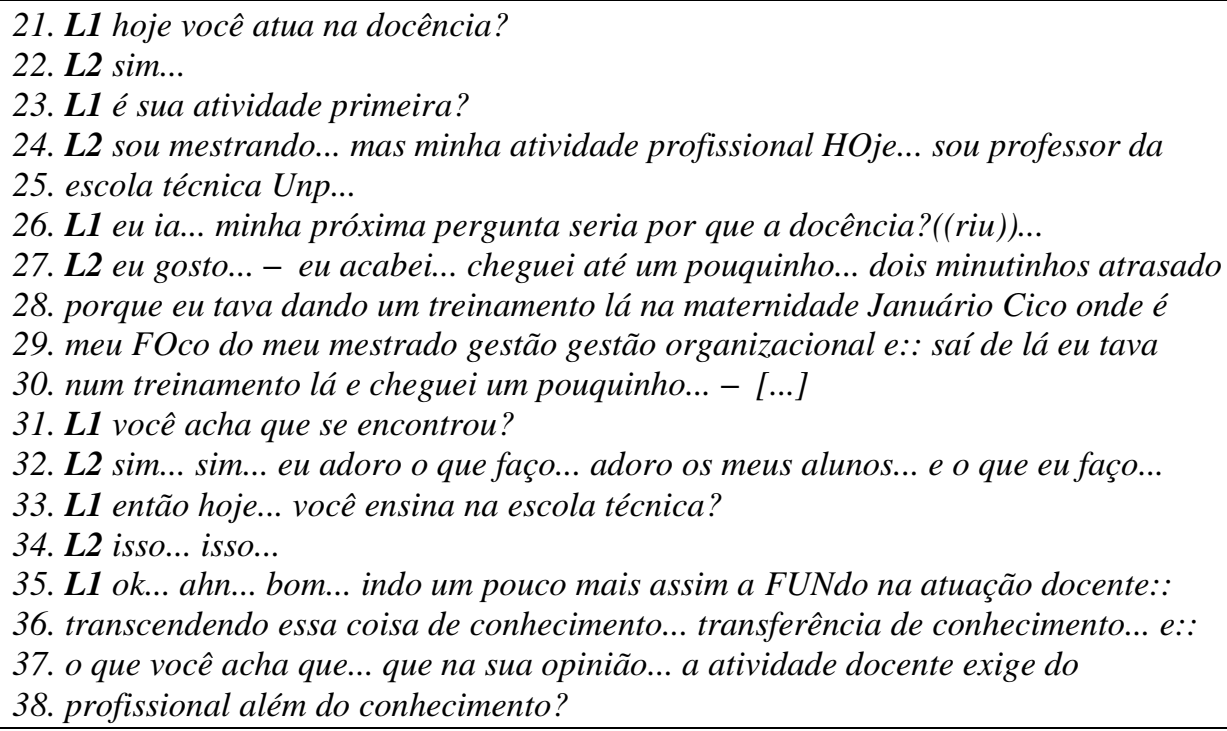

Com relação ao planejamento, fica claro que o entrevistador (L1) tinha perguntas previamente elaboradas. Isso fica evidente na linha 26 da EE02 quando L1 diz: "eu ia... minha próxima pergunta seria por que a docência?". Tal pergunta foi pensada a partir de informações que L1 obteve com os dados oferecidos por L2, e principalmente por meio do currículo impresso. Assim, cada tópico foi planejado por L1, tendo em vista os objetivos, as informações que almejava alcançar.

Quanto ao par "pergunta-resposta", esse é configurador da entrevista de seleção de emprego. Os falantes, assumem as posições estabelecidas pelo gênero e comportam-se de maneira a fazer progredir a entrevista. Com isso, as intenções de L1, em obter informações, e a de L2, em fornecer informações necessárias, materializam-se na estrutura da entrevista, imprimem um caráter vivo ao evento discursivo.

No que se refere à assimetria, essa é visível nas linhas 21 a 38 da EE02, nos movimentos operados por L1 em conduzir os tópicos da entrevista. É importante dizer que a posição de L1 é a de representante da instituição, cabendo-lhe o papel de conduzir a entrevista. Nessa relação social, são as perguntas que instauram os tópicos. No trecho da EE02 em destaque, percebe-se que algumas perguntas postuladas por L1, promovem a construção de tópicos e a progressão da entrevista: (21) "hoje você atua na docência?" (23) "é sua atividade primeira?" (26) "[...] minha próxima pergunta seria por que a docência?" (31) "você acha que se encontrou?" (33) "então hoje... você ensina na escola técnica?" (37-38) "o que você acha que... que na sua opinião... a atividade docente exige do profissional além do conhecimento?”.

\section{ELEMENTOS DA ORALIDADE E DO ESTILO LINGUÍSTICO DO GÊNERO}

\author{
Revista de Gestão e Secretariado-GeSec, São Paulo, v. 8, n. 2, p 107-227, Mai./Ago.
}

2017. 
O gênero entrevista de seleção de emprego, por ser um gênero oral, apresenta algumas características linguísticas e alguns elementos típicos da oralidade que merecem ser apontados aqui. Alguns desses elementos linguísticos recorrentes nas entrevistas são: entonação, repetição, mudança de locutor, processos de inserção, entre outros, próprios da oralidade. A entrevista de seleção de emprego é uma prática social mediada principalmente pela linguagem oral - as perguntas e as respostas são geralmente orais.

A entonação, para Jubran (2006), representa um dos mecanismos mais eficazes usados pelos falantes para dar ênfase a um determinado assunto sobre o qual falam, bem como seus propósitos comunicativos. Nessa direção, pode-se considerar que a entonação é um recurso que, entre outras coisas, marca ênfase, imprime uma visão avaliativa, marca uma subjetividade e, assim, o locutor pode influenciar o interlocutor.

A repetição é um dos elementos mais recorrentes na fala dos interlocutores durante a entrevista. Conforme assinala Koch (2010), a repetição é um recurso do texto falado e pode desempenhar diversas funções.

O exemplo ilustrado a seguir traz um pequeno trecho da EE02 em que é frequente o recurso da repetição no discurso principalmente do entrevistado.

\section{Entrevista de seleção de emprego 02 (EE02)}

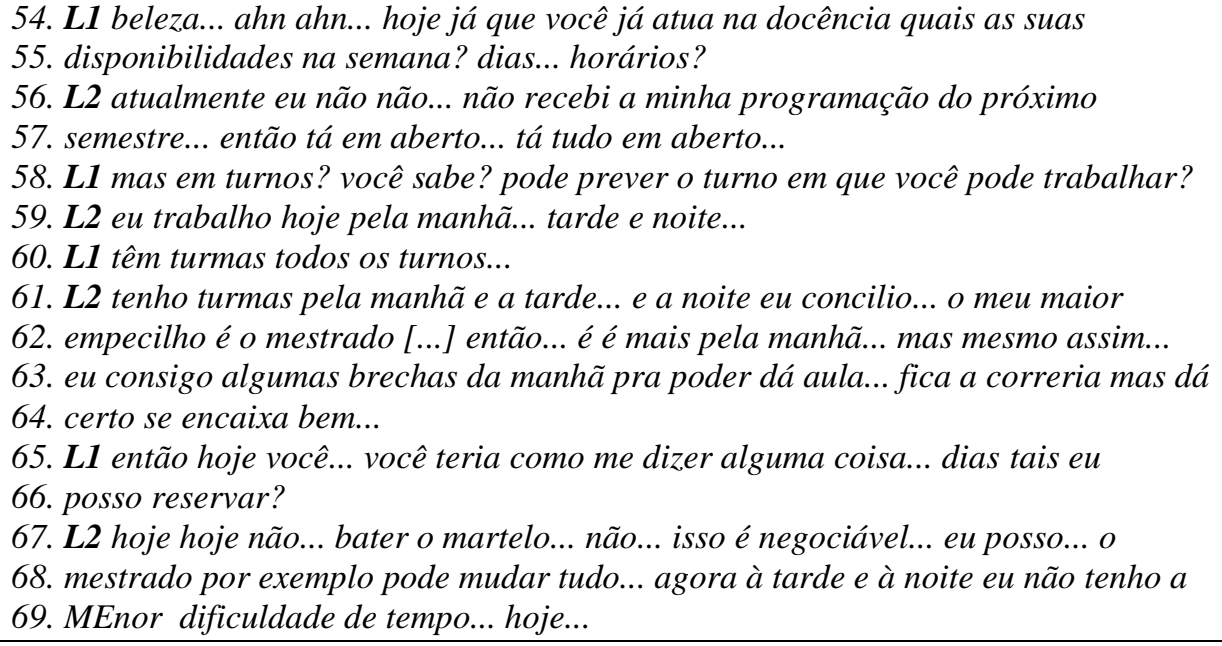

Ao responder a uma pergunta feita por L1 sobre a disponibilidade durante a semana, L2 repete três vezes o advérbio "não" e, logo em seguida, repete a expressão "tá em aberto", com o intensificador "tudo" marcando a forma repetida: "atualmente eu não não... não recebi a minha programação do próximo semestre... então tá em aberto... tá tudo em aberto". No primeiro caso, ocorre uma repetição exata. No segundo, acontece uma pequena variação, aproximando-se de uma paráfrase.

Na primeira ocorrência "não não...não", a repetição é marcada no início da oração, momento em que L2 processa uma resposta. É um recurso, portanto, que possibilita ao falante não silenciar diante da pergunta e, ao mesmo tempo, processar uma resposta satisfatória. Esse aspecto salienta o que diz Koch (2010) quando postula que a interação face a face é localmente planejada, ou seja, a cada novo momento do diálogo, os falantes vão construindo um fluxo discursivo. Cabe sublinhar que isso ocorre quase que de forma automática, sendo um elemento presente nos processos interativos verbais do cotidiano. 
Já a segunda repetição "tá em aberto... tá tudo em aberto" sinaliza para algo mais complexo. Nesse caso, o efeito de ênfase é construído. L2 reforça e enfatiza a resposta dada de que não tinha recebido a programação do próximo semestre e, portanto, não poderia discutir sobre a disponibilidade de tempo - "tá tudo em aberto" quanto a isso. É possível observar também que tal repetição parece causar um determinado efeito sobre L1, no sentido de que este último constrói a pergunta seguinte a partir da resposta enfática de L2.

O mesmo trecho em destaque serve para ilustrar outro elemento do gênero entrevista: a mudança de locutor. No ato da entrevista, os interlocutores estão numa relação face a face e o diálogo é marcado pelas alternâncias, pelos turnos de fala. Geralmente, o final do turno da fala de L1 é marcado por uma pergunta. Por outro lado, L2 costuma marcar os finais de fala com uma afirmação, uma resposta, e dificilmente com uma pergunta, conforme exemplifica o trecho em questão. Mas isso não é unanimidade, tendo em vista os casos em que L2 faz perguntas retóricas com valor argumentativo durante a construção da resposta.

Os postulados de Bakhtin (2011) constam que o primeiro traço fundamental do enunciado é a alternância dos sujeitos do discurso. Essa alternância abarca todos os enunciados, visto que todos eles têm um princípio absoluto e um fim absoluto, a saber: antes do seu início, os enunciados de outros; depois do seu término, os enunciados responsivos de outros. Diante disso, infere-se a compreensão de que é o fato de o enunciado ser produzido em meio a outros enunciados, sendo produzido em diálogo com eles, que a alternância dos sujeitos do discurso se configura. Isso acontece porque todo enunciado, numa concepção bakhtiniana, nasce em resposta a outro enunciado e ao mesmo tempo convoca uma resposta subsequente.

Cada enunciado, ou cada réplica, nos dizeres de Bakhtin (2011, p. 275), “[...] por mais breve e fragmentária que seja, possui uma conclusibilidade específica ao exprimir certa posição do falante que suscita resposta, em relação à qual se pode assumir uma posição responsiva." No caso do gênero entrevista de seleção de emprego, em alguns casos, a alternância de locutores é marcada por pequenos marcadores linguísticos, como no trecho extraído da EE01 seguinte:

\section{Entrevista de seleção de emprego 01 (EE01)}

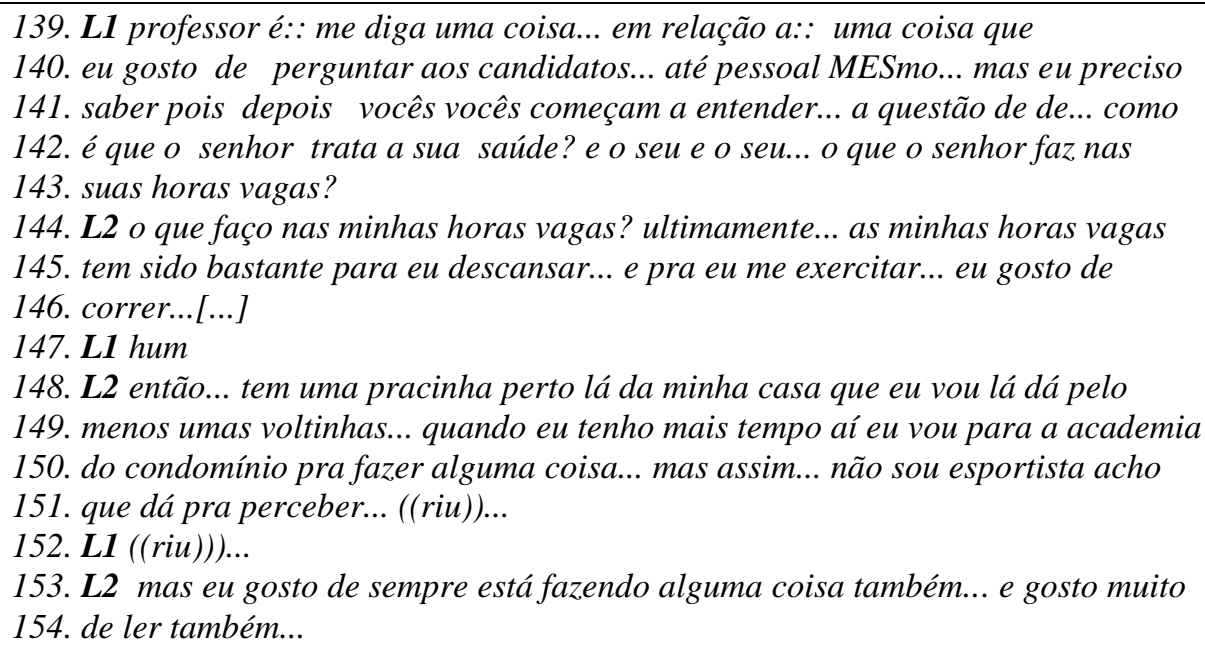

Conforme é possível observar na linha 147 da EE01, apenas a expressão "hum" sinaliza a alternância de interlocutor. Tal expressão estabelece um contato entre Revista de Gestão e Secretariado-GeSec, São Paulo, v. 8, n. 2, p 107-227, Mai./Ago. 
os participantes do diálogo. Essa expressão se situa no meio da resposta fornecida por L2 que, ao ser questionado sobre o que costuma fazer nas horas vagas, informa que tem aproveitado para descansar e "gosta de correr". No meio da resposta, L2 faz uma pausa e L1 intervém com a expressão "hum", estabelecendo um apoio, uma confirmação com o dito. Logo em seguida, L2 continua desenvolvendo sua resposta dando detalhes do lugar onde costuma correr: "então... tem uma pracinha perto lá da minha casa que eu vou lá dá pelo menos umas voltinhas [...]".

Essa alternância dos interlocutores do discurso faz com que as réplicas sejam interligadas, ou seja, não existem enunciados produzidos fora do diálogo, fora do mundo das palavras de outrem. Em outros termos, não há como enunciar fora da réplica e fugir do encontro com os outros enunciados sempre presentes no momento da enunciação. Vale ressaltar que as ocorrências como essas evidenciam o fato de que, na construção da entrevista, temos a coprodução discursiva dos interlocutores. Eles estão juntamente empenhados na produção do texto. Nos termos de Koch (2010, p. 79), "[...] eles não só colaboram um com outro, como 'co-negociam', 'co-argumentam', a tal ponto que não teria sentido analisar separadamente as produções individuais". Isso se aplica perfeitamente às produções dos falantes durante a entrevista de seleção de emprego. Cada pergunta ou resposta é construída na interação entre os participantes, formando uma unidade.

Quanto aos processos de inserção, Koch (2010) mostra que as inserções constituem segmentos discursivos que provocam uma espécie de suspensão temporária do tópico em curso. Na construção da entrevista de seleção de emprego, é perceptível esse processo quando um dos participantes suspende o tópico e introduz uma explicação.

A fim de exemplificar o processo de inserção, selecionamos o trecho a seguir extraído da EE02.

\section{Entrevista de seleção de emprego 02 (EE02)}

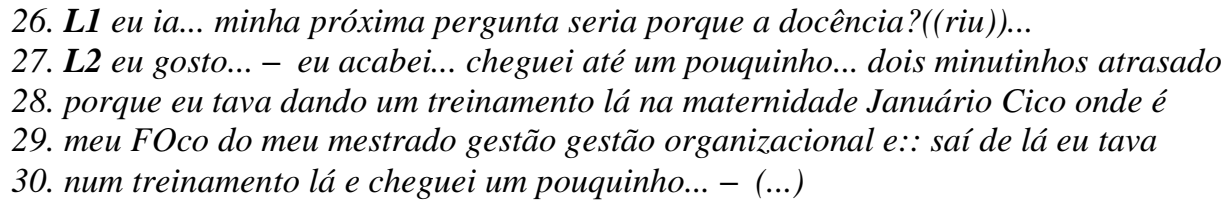

26. L1 eu ia... minha próxima pergunta seria porque a docência?((riu))...

27. L2 eu gosto... - eu acabei... cheguei até um pouquinho... dois minutinhos atrasado

28. porque eu tava dando um treinamento lá na maternidade Januário Cico onde é

29. теи FOco do meu mestrado gestão gestão organizacional e:: saí de lá eu tava

30. num treinamento lá e cheguei um pouquinho... - (...)

Observa-se que, ao ser questionado sobre a docência, L2 afirma que gosta, mas muda imediatamente e introduz uma explicação para justificar seu atraso à entrevista: "- eu acabei... cheguei até um pouquinho... dois minutinhos atrasado porque eu tava dando um treinamento lá na maternidade Januário Cico onde é meu Foco do meu mestrado gestão gestão organizacional e:: saí de lá eu tava num treinamento lá e cheguei um pouquinho... - [...]". Assim, L2 ao invés de explicar o porquê da sua escolha pela carreira docente resolve se afastar desse tópico, que foi introduzido por L1, e escolhe outro tópico para esclarecer o motivo do seu atraso. Ou seja, essa justificativa, pelo menos aparentemente, não desempenha qualquer função relativa ao tópico em curso. Observa-se, portanto, a quebra do fio discursivo. Conforme afirma Koch (2010, p. 113) as inserções constituem um fenômeno bastante corriqueiro na conversação. "De modo geral, elas não só não prejudicam a coerência, mas, pelo contrário, muitas vezes ajudam a construí-la”. 


\section{CONSIDERAÇÕES FINAIS}

Retomando a perspectiva bakhtiniana de gênero como "formas relativamente estáveis de enunciados" e, concordando que o enunciado reflete não só as condições específicas, como também as finalidades de cada esfera da atividade humana, prosseguimos com o pensamento do autor, ao dizer que os gêneros discursivos são demarcados a partir do conteúdo temático, da construção composicional e do estilo verbal.

Aplicando esses princípios ao corpus investigado, no que diz respeito ao conteúdo temático, percebe-se que a entrevista de seleção de emprego - voltada para a seleção de professores para atuar no nível técnico profissionalizante, especificamente para as áreas de Logística, Radiologia Veterinária e Vigilância em Saúde - trata de temas relativos à experiência profissional, disponibilidade de tempo, planejamento de aula, remuneração, horário, local das aulas e perfil dos alunos, além de uma introdução cujo objetivo é abrir esse evento social com os cumprimentos e a contextualização do processo seletivo e também de um encerramento composto de agradecimentos e de informações relacionadas às próximas fases do processo seletivo. Cada um desses temas é construído a partir da interação, do diálogo entre os participantes, e todos esses temas têm seus propósitos discursivos.

Quanto à construção composicional, observa-se que a entrevista de seleção de emprego é um gênero que organiza um evento oficial dentro de uma esfera social, coordenado por um representante legal com poderes para conduzir o evento, por meio de questionamentos relativos ao propósito do cargo. A estrutura é relativamente estável, pois as entrevistas analisadas apresentam uma introdução, que marca a abertura do evento, na qual está presente a contextualização do processo seletivo, seguida das perguntas e respostas em torno do objetivo do cargo e, por último, traz uma conclusão que é composta de felicitações, agradecimentos e informes acerca das demais fases da seleção.

Sobre o estilo, nota-se que os locutores fizeram uso da entonação de ênfase; da repetição; de marcadores conversacionais de concordância e de construções frasais na interrogativa. As construções frasais são introduzidas pelos entrevistadores, que são os responsáveis por conduzir desde a introdução até a conclusão da entrevista, caracterizando, assim, a assimetria do gênero, por meio do estabelecimento dos papéis de cada participante. Os entrevistados por sua vez, normalmente apresentam as respostas fornecendo as informações solicitadas, porém, busca-se, na maioria das vezes, o acordo dos entrevistadores por meio do uso de marcadores conversacionais de concordância tais como: "certo" e "entende", com o objetivo de solicitar a confirmação da sua fala. Desse modo, por meio da interação face a face, das escolhas lexicais dos locutores, o gênero é arquitetado através da participação ativa do entrevistador e do entrevistado e, cada pergunta ou resposta, é construída na interação entre os participantes, formando assim uma unidade.

Perante essa compreensão, é possível inferir que os relatos contempladores desse evento social não ocorrem dissociados do contexto. Os locutores têm consciência de que fazem parte de um contexto histórico e cultural no qual estão inseridos e, assim, fazem uso de determinados elementos linguísticos para atribuir sentido, importância e para dar ênfase ao conteúdo veiculado. Assim, avaliam seus compromissos através da escolha de expressões e fenômenos linguísticos, e tal escolha não é feita aleatoriamente. Na verdade, a utilização de determinadas formas e expressões, em um enunciado, revela 
posicionamentos e orientações por parte dos locutores, entrevistadores e entrevistados, o que ficou evidente no gênero aqui estudado.

Desse modo, a inserção de cada elemento linguístico materializado nos discursos dos locutores compreende uma orientação discursiva, apresenta nuances axiológicas que variam de acordo com o posicionamento ocupado pelo locutor, orientação essa que compõe a teia discursiva que constitui o gênero entrevista de seleção de emprego (Bakhtin, 2011).

Por fim, o gênero entrevista de seleção de emprego é um gênero da esfera empresarial ligado ao processo de recrutamento e seleção de pessoal e, nesse processo, este gênero funciona como palco do encontro entre vozes (L1 e L2), em que o estilo, a construção composicional e o conteúdo temático são construídos a partir do encontro entre as perguntas e as respostas.

\section{REFERÊNCIAS}

Bakhtin, M. M. (2011). Estética da criação verbal (6a ed.). São Paulo: WMF Martins Fontes.

Bakhtin, M. M. \& Voloshinov, V. N. (2009). Marxismo e filosofia da linguagem: problemas fundamentais do método sociológico da linguagem (13a ed.). São Paulo: Hucitec.

Espíndola, L. C. (2004). A entrevista: um olhar argumentativo. João Pessoa: EDUFPB.

Fávero, L. L. (2000). A entrevista na fala e na escrita. In Preti, Dino. (Org.) Fala e escrita em questão. São Paulo: Humanitas.

Fávero, L.L., Andrade, M. L. C. V. O. \& Aquino, Z. G. O. (2005). Oralidade e escrita: perspectivas para o ensino de língua materna (5a ed.). São Paulo: Cortez.

Faraco, Carlos Alberto. (2003). Linguagem e diálogo: as idéias linguísticas do círculo de Bakhtin Curitiba: Criar.

Gil, A. C. (1999). Métodos e técnicas de pesquisa social. São Paulo: Atlas.

Jubran, C. C. A. S. (2006). Tópico discursivo. In Jubran, C. C. A. S. \& Koch, I. G.V. (Org). Gramática do português culto falado no Brasil. Campinas: Editora da Unicamp.

Koch, I. G.V. (2010). A inter-ação pela linguagem (10a ed.. São Paulo: Contexto.

Marcuschi, L. A. (1986). Análise da conversação. São Paulo: Ática.

Assimetria, poder e adequação na interação verbal. (1995). In Investigações: linguística e teoria literária. (Org.) Dino Preti. São Paulo: Humanistas/FFLCH/USP, vol. 5, dez, pp. 80-93. 
Nascimento, E.P. \& Silva, J. M. (2012). O fenômeno da Modalização. In Nascimento, E. P. A redação comercial oficial: estratégias semântico-discursivas em gêneros formulaicos. João Pessoa: Editora Universitária/UFPB. 